\title{
IMPACT OF PRECEDING HANDSPRING UPON KINEMATIC CHARACTERISTICS OF DIFFERENT SALTO BACKWARDS
}

\author{
Emil Stoimenov, Iliya Kiuchukov, Iliya Yanev
}

Summary

A comparison is made between salto backwards of different complexity, performed after round off and back handspring (salto backwards stretched, double salto backwards tucked and salto backwards stretched with $2 \backslash 1$ twist).

Six competitive gymnasts performed salto backwards stretched, double salto backwards tucked and salto backwards stretched with $2 \backslash 1$ twist from round off and backward handspring. The performances were videotaped with a $60 \mathrm{~Hz}$ video camera and analyzed independently utilizing the Ariel Performance Analysis System (APAS). The best gymnast's performances were selected for analysis. The left foot; the knee, shoulder, and elbow joints; the hand, and the top of the head digitized. The raw data were digitally smoothed with a cut-off frequency of $7 \mathrm{~Hz}$ before being submitted to further analysis. Data from the APAS were transferred to Microsoft EXCEL for further processing and presentation of results. $B y$ the means of kinematic analysis, differences are found between the studied exercises. For the three exercises considered, higher kinematic values of the vertical component of the center of gravity velocity were established at the time of take-off of gymnast from the floor in the backward salto performance.

By the means of kinematic analysis, differences are found between the studied exercises. For the three exercises considered, higher kinematic values of the vertical component of the center of gravity velocity were established at the time of take-off of gymnast from the floor in the backward salto performance.

The obtained results can be used in optimization of the training process of teenage and elite gymnasts.

Key words: Artistic gymnastics, floor, variation in technique

\section{Introduction}

There is a constant striving towards increasing the efficiency of the motor motionseducation. According to each sport's specific features, the most rational approaches are searched for solving of variety of motor problems. In order to achieve the correct motor progress of the educated sportsmen, the sport pedagogue must have a profound knowledge about the biomechanics peculiarities of the motor events. Various aspects of the performance technic of floor exercises arouse the interest of a number of researchers. Geiblinger et al. (1995) examine some biomechanics characteristics at the performance of double salto backwards on floor exercise. R. Burgess и G. Noffal (2001) discuss difference of such indices as speed, touchdown angle, duration of the last supporting phase at saltos backwards performed by gymnasts with different qualification. P. Hedbávný, M. Kalichová (2011) examine the relation between the amount of rotation of the body around the longitudinal axis and touchdown angle at the last phase of the supporting period. Mkaouer et al. (2013) compare the biomechanics characteristics of salto backwards stretched, performed after back handspring and after tempo salto backwards. Farana et al. (2013) examine the influence of various options of placing of the hands at round off on reaction force and elbow joint torque.
A comparison is made between salto backwards of different complexity, performed after round off and back handspring (salto backwards stretched, double salto backwards tucked and salto backwards stretched with $2 \backslash 1$ twist).

\section{Methodology}

Six competitive gymnasts performed salto backwards stretched, double salto backwards tucked and salto backwards stretched with $2 \backslash 1$ twist from round off and backward handspring. The performances were videotaped with a $60 \mathrm{~Hz}$ video camera and analyzed independently utilizing the Ariel Performance Analysis System (APAS). The best gymnast's performances were selected for analysis. The left foot; the knee, shoulder, and elbow joints; the hand, and the top of the head digitized. The raw data were digitally smoothed with a cut-off frequency of $7 \mathrm{~Hz}$ before being submitted to further analysis. Data from the APAS were transferred to Microsoft EXCEL for further processing and presentation of results. Position of CG during saltos, horizontal speed of CG, angle formed between the horizontal and the connecting line of CG and the contact point of the feet with the support (touchdown angle and take off angle) are calculated (fig. 1). 


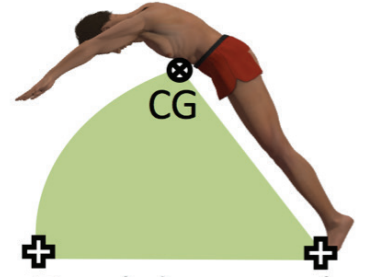

Touchdown angle

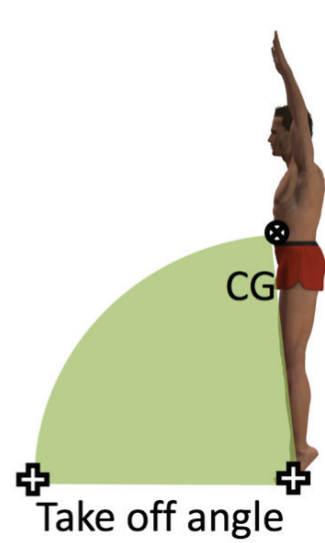

Figure 1. Touchdown angle and take off angle

\section{Results}

By the means of kinematic analysis, differences are found between the studied exercises. For the three exercises considered, higher values of the vertical component of the center of gravity velocity were established at the time of take-off of gymnast from the floor in the backward salto performance.

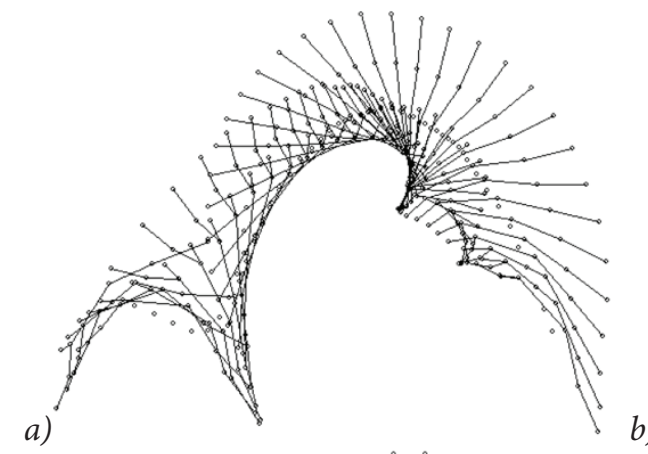

b)

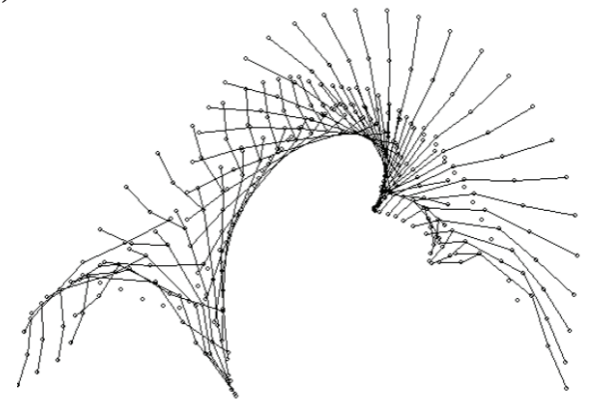

Figure 2. Salto backwards stretched after round off (a) and back handspring (b)

Performance of salto backwards stretched after round off (fig. 2a) touchdown angle is 47 degrees (fig. 3a), and after back handspring 53 degrees (fig. 3b).

Take off angle after round off is 86 degrees (fig. 3c), after back handspring this angle is 83 degrees (fig. 3d). Horizontal speed after performance basic acrobatic gymnastics skills (round off and back handspring) before touchdown moment at performance round off is $4,60 \mathrm{~m} / \mathrm{s}$ and $4.75 \mathrm{~m} / \mathrm{s}$ after back handspring. Regarding the height of both saltos, salto backwards stretched performed after back handspring is $2,46 \mathrm{~m}$ (fig. $4 \mathrm{~b}$ ), which is $10 \mathrm{~cm}$ higher than performance after round off - 2,36 m (fig. 4a).

a)

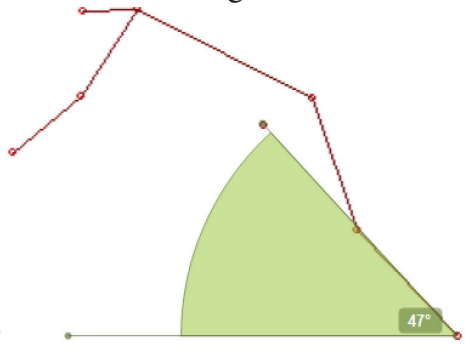

b) .

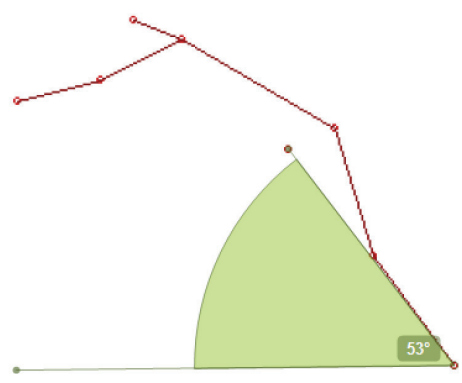

c)

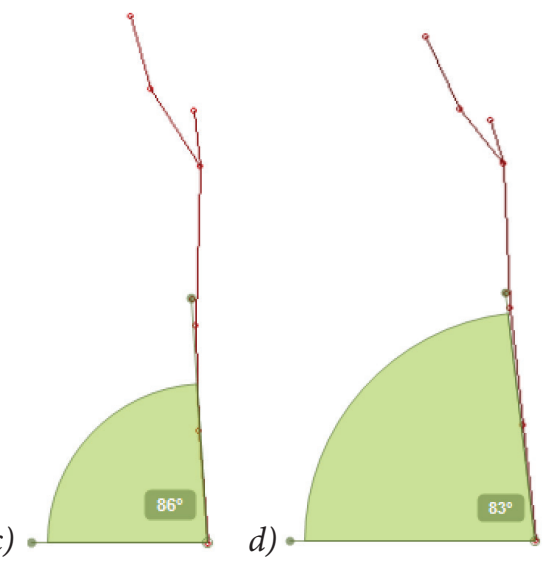

Figure 3. Touchdown and take off angle after round off and back handspring at salto backwards stretched
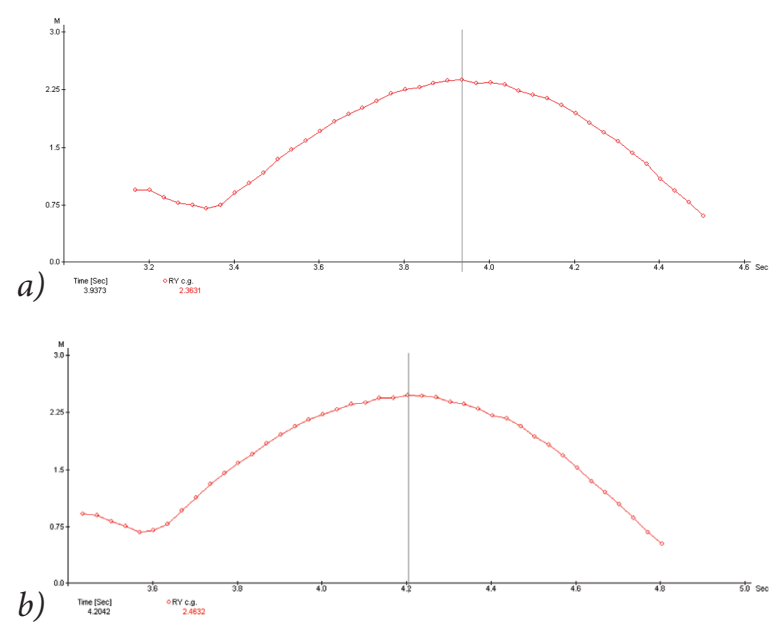

Figure 4. Position of CG at salto backwards stretched 
performed after round off (a) and back handspring (b)

a)

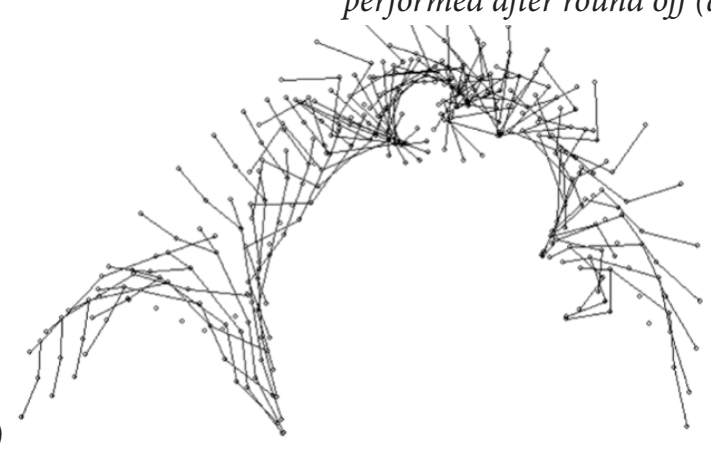

Figure 5. Double salto backwards tucked performed after round off (a) and back handspring (b)

It was found out that at performance of double salto backwards, touch down angle after round off entry is 51 degrees (fig. 6a), and after back handspring is 47 degrees (fig. 6b). In take-off phase angle is 81 degrees (fig. 6c) after round off and 81 degrees (fig. 6d) after back handspring. The horizontal speed after performance of both kinds of preparatory turns, is respectively $4.2 \mathrm{~m} / \mathrm{s}$ after round off entry and $4.54 \mathrm{~m} / \mathrm{s}$ after back handspring. Vertical CG offset, both in the salto backwards stretched and in the double salto backwards has a higher value after a back handspring $-2.52 \mathrm{~m}$ (fig. 7b) against $2.40 \mathrm{~m}$ (fig. 7a) performed after round off.

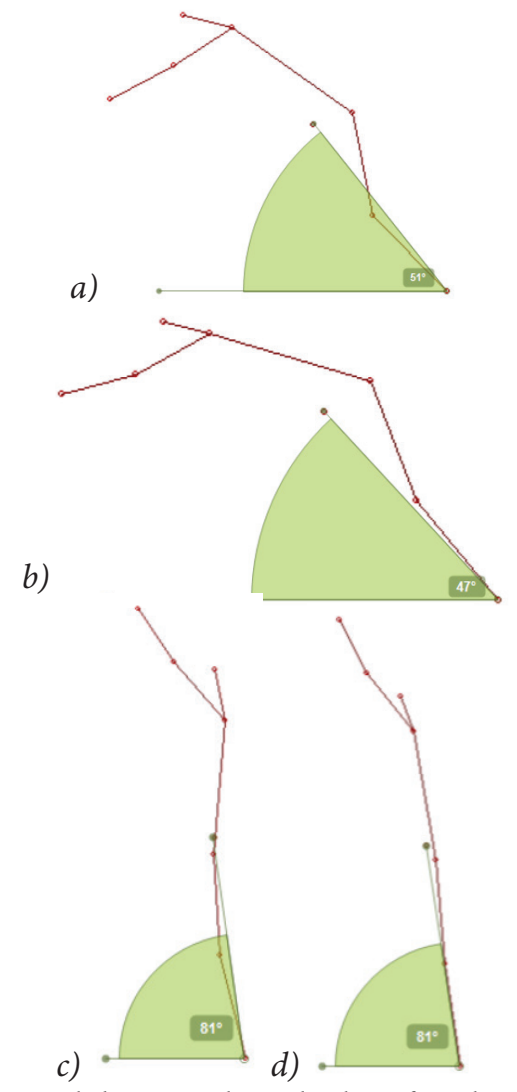

Figure 6. Touchdown angle and take off angle after round off and back handspring at double salto backwards b)
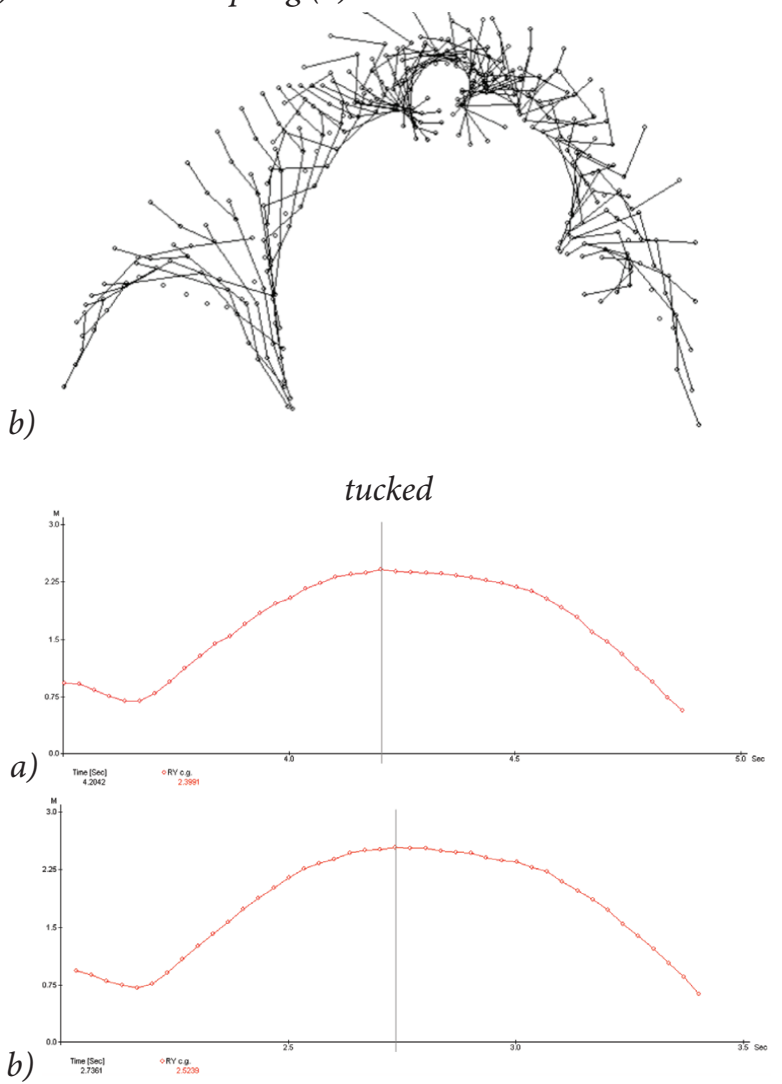

Figure 7. Position of CG at double salto backwards tucked performed after round off (a) and back handspring (b)

a)

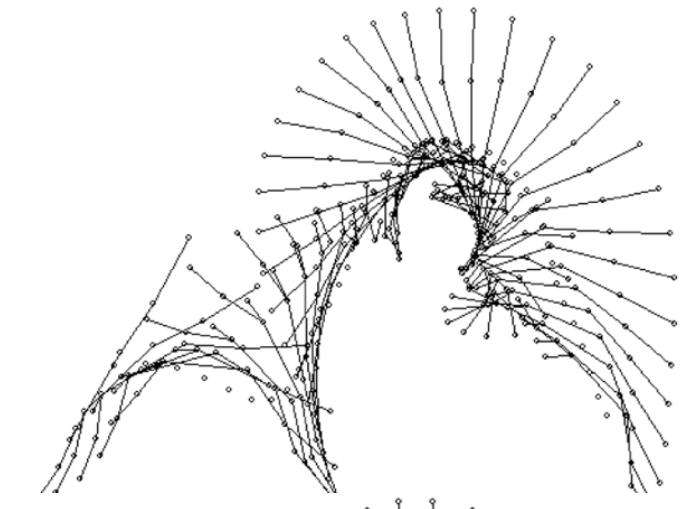

b)

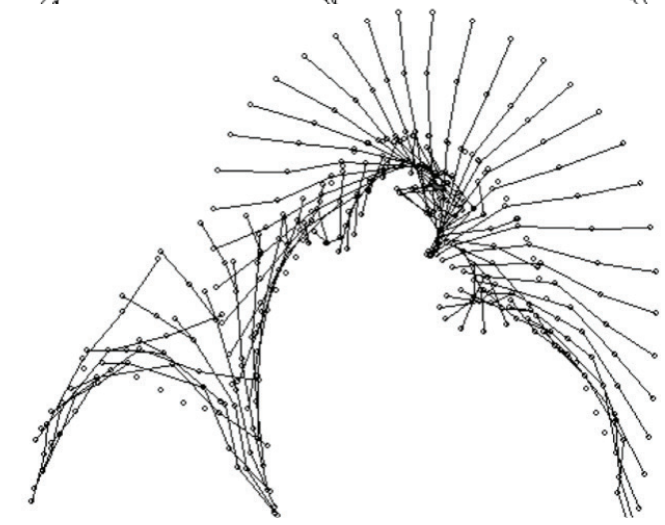

Figure 8. Salto backwards stretched with $2 \backslash 1$ twist performed after round off (a) and back handspring (b) 
a)

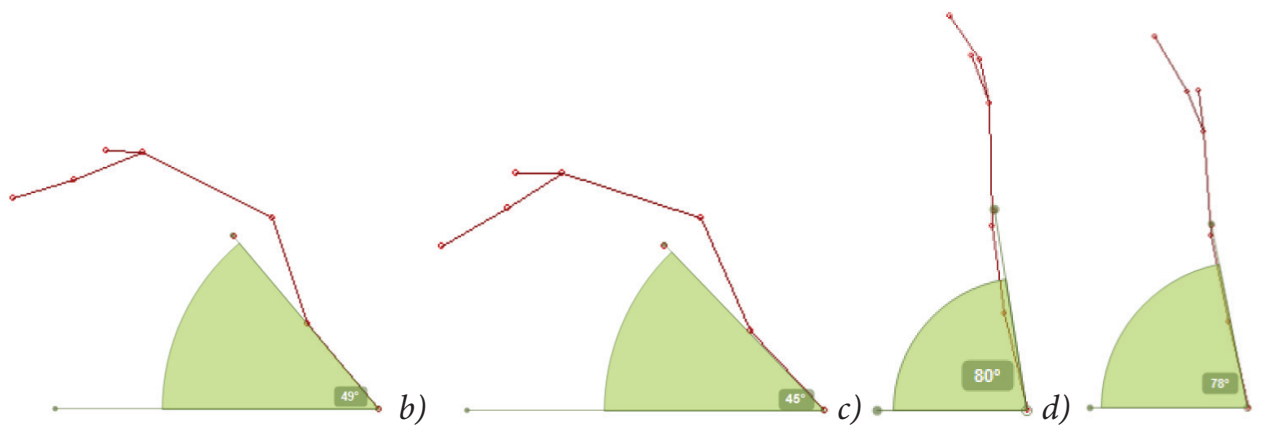

Figure 9. Touchdown angle and take off angle after round off and back handspring at salto backwards stretched with $2 \backslash 1$ twist

a)
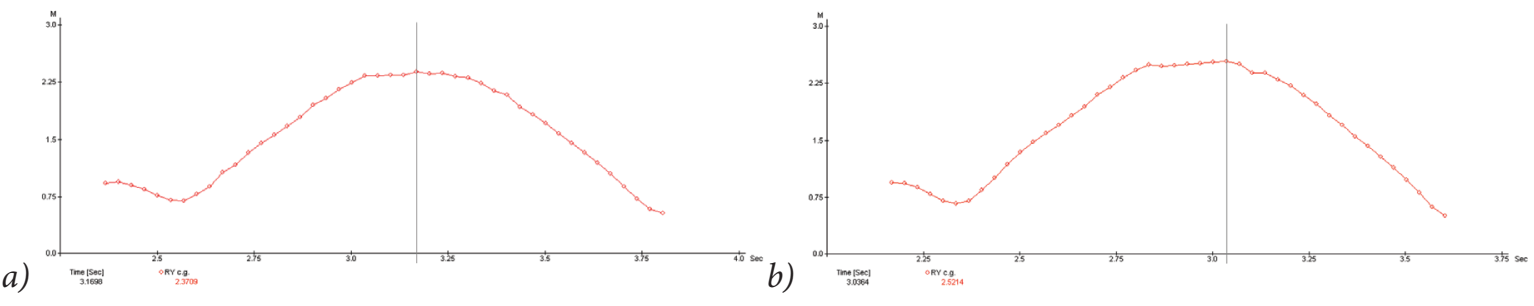

Figure 10. Position of CG at salto backwards stretched with $2 \backslash 1$ twist performed after round off (a) and back handspring (b)

At performance of salto backwards stretched with $2 / 1$ twist after round off and back handspring the touchdown angle is 49 degrees (fig. 9 a) after round off and 45 degrees (fig. 9b) after back handspring. The take-off angle is 80 degrees in performance after round off (fig. 9c) and 78 degrees after back handspring (fig. $9 \mathrm{~d})$. The horizontal speed during execution of the two types of preliminary handsprings is $4.09 \mathrm{~m} / \mathrm{s}$ after round off and $4.68 \mathrm{~m} / \mathrm{s}$ after back handspring. About the height, there are advantages in performance from back handspring where the height is $2.52 \mathrm{~m}$ (fig. 10b), which is $15 \mathrm{~cm}$. higher than the performance after a round off entry, which is $2.37 \mathrm{~m}$ (fig. 10a).

\section{Discussion}

The performance capacity of the flight phase depends on the sportsman's actions in the final phase of the supporting period. The angular momentum, necessary for the non-support period, is provided by the acquired motion of the previous exercises (for example by round off or back handspring) and the added rotational impulse, as a result of the gymnast's actions in the last phase before the takeoff from the support.

The comparative analysis of the studied exercises established that after the performance of back handspring the horizontal speed of CG is higher compared to the performance after round off entry. The analysis showed that during performing of various saltos backward performed after back handspring a bigger height is achieved. The main indicator for a high level of performance and the ability to complicate an exercise is "the height of the salto". Research of impact of preceding handspring upon kinematic characteristics of different salto backwards, means that backward handspring before the main exercise leads to better conditions for its performance.

\section{Conclusions}

The knowledge of biomechanical regularities of the transition from support to flight phase may be useful for the pedagogue at the analysis of the performer's actions in practice. The established data refer to a limited number of performances. In our opinion, the performance of a bigger number of competitors shall be analyzed in order to achieve more definiteness of the conclusions in our future studies. The obtained results can be used in optimization of the training process of young and elite gymnasts. The study shows the quantitative advantages of the various preceding handspring, which can help the work of the coaches. 


\section{References}

Burgess, R., G. Noffal. (2001), Kinematic analysis of the back salto take-off in a tumbling series: advanced vs. beginner techniques. 19 International Symposium on Biomechanics in Sports, San Francisco USA.

Farana, R., D. Jandacka, J. Uchytil, D. Zahradnik and G. Irwin (2013), The effect of different hand position on impact forces and elbow loading during the round off in female gymnastics. 31 International Symposium on Biomechanics in Sports Taipei, Taiwan.

Geiblinger, H., W. E. Morrison \& P. A. McLaughlin.
(1995), Take-off characteristics of double back somersaults on the floor. 13 International Symposium on Biomechanics in Sports. Thunder Bay Ontario, Canada, pp. 142-146.

Hedbávný, P., M. Kalichová. (2011), Analysis of Take-off Phase of Somersaults with Twisting along the Longitudinal Body Axis. World Academy of Science, Engineering and Technology, 59, 2011, pp 590-593.

Mkaouer, et al. (2013), Kinematic and Kinetic Analysis of Two Gymnastics Acrobatic Series to Performing the Backward Stretched Somersault. Journal of Human Kinetics vol. 37, pp.17-26. 